\title{
When less is more: mitigating the harms and risks of over-testing through shared decision making
}

\author{
Anthony Chauvin ${ }^{1,2}$ (1) $\cdot$ Eddy Lang $^{3} \cdot$ Patrick Bossuyt $^{4}$
}

Received: 27 July 2021 / Accepted: 5 November 2021 / Published online: 18 November 2021

(c) The Author(s), under exclusive licence to Canadian Association of Emergency Physicians (CAEP)/ Association Canadienne de Médecine d'Urgence (ACMU) 2021

Keywords Emergency medicine $\cdot$ Over-testing

Over-testing refers to the ordering of imaging or laboratory tests that provide little or no value in clarifying a diagnosis or in guiding the management of a patient [1]. The causes of over-testing are myriad and include fear of malpractice, desire for diagnostic certainty (reassurance), inadequate clinical decision support, habit and inertia, misuse of decision rules, educational gaps, patient expectations, perverse financial incentives, and the overall complexity of emergency care.

In 2015, Kanzaria et al. conducted a survey of 478 emergency physicians to understand their perceptions regarding the extent to which they order medically questionable advanced diagnostic imaging (computed tomography or ultrasound). The authors highlighted that $85 \%$ of respondents confessed to ordering clinically irrelevant lab tests and that $97 \%$ were "certain" that they themselves had ordered medically questionable imaging tests [2]. Despite awareness of the phenomenon of over-testing, perceptions vary as to whether it is a significant problem in emergency medicine.

The harms and costs of over-testing are becoming increasingly evident. Aside from the financial impact, resources consumed are taken away from other emergency department

Anthony Chauvin

anthony.chauvin@aphp.fr

1 Emergency Department and PreHospital EMS, Service d'Accueil des Urgences/SMUR, Lariboisière's Hospital, Assistance Publique Hôpitaux de Paris, Paris University, 2 rue Ambroise Paré, 75010 Paris, France

2 Inserm U942 MASCOT, Université de Paris, Paris, France

3 Department of Emergency Medicine, Cumming School of Medicine, University of Calgary, Calgary, AB, Canada

4 Department of Epidemiology and Data Science, Amsterdam Public Health, Amsterdam UMC, University of Amsterdam, Amsterdam, the Netherlands
(ED) patients in need. While precise estimates of the costs of over-testing in emergency departments are lacking, we know that ED is a high-cost clinical setting, often demonstrating an unsustainable rate of growth. The direct cost per ED visit has risen from \$96 in 2005-2006 to \$158 in 2018-2019, an average annual growth rate of $4 \%$. Paradoxically, increased healthcare costs for tests and treatment are not linked to better outcomes [3].

One increasingly recognized harm of testing is overdiagnosis. In its essence, overdiagnosis refers to labeling a patient with a medical condition that was never going to cause harm, abnormalities that do not progress, that progress too slowly to cause symptoms or harm during a person's remaining lifetime, or that resolve spontaneously. One of the most well-described examples of this is the sub-segmental pulmonary embolism (PE). As computed tomography pulmonary angiogram technology has become increasingly higher resolution and more sensitive in diagnosing PE, clinicians have also started to use this test more frequently in the last 10 years, without a reduction in PE mortality. This suggests that the rise is due to the detection of less clinically significant disease that likely does not benefit from treatment [4].

The dilemma between performing many tests based on practice patterns versus selecting tests based on clinical probability is a daily occurrence in emergency medicine. Many studies have shown a link between length of stay in the ED and the number of tests performed [5]. Over-testing is an important contributor to ED overcrowding, which has been shown to result in increased morbidity and mortality among all ED patients [6].

Curbing over-testing could be possible through actions taken at all stakeholder levels. One potential solution would be a stronger focus and reliance on patient-oriented outcomes from studies evaluating the utility and impact 
of diagnostic tests [7]. Diagnostic test research has rarely focused on patient-important outcome measures, often failing to go beyond traditional metrics of test accuracy. In cases where the new diagnostic test is safer, cheaper, faster, and more available than the old test, randomized controlled trials are not required for approval [8]. Unfortunately, most new diagnostic tests do not meet these criteria, but are nevertheless incorporated into practice after studies on clinical performance are completed but without trials that document the effects on patient-important outcome measures. To avoid or reduce over-testing in the emergency department, individual awareness should be coupled with collective improvement efforts. The perils of testing should be highlighted at all levels of education and training, for physicians, students and nurses. Benchmarking between departments and comparison of physician test ordering patterns could highlight unexplained variation in the number of tests that are being performed.

Making patients and practitioners understand that "more is not necessarily better" will require a paradigm shift in the doctor-patient relationship and the creation of engaged, savvy, informed, skeptical and informed patients and families. To this end, the Choosing Wisely ${ }^{\circledR}$ campaign provides, for both patients and physicians, lists of medical practices specific to each specialty that are frequently used, costly, and whose benefit-risk balance may be unfavorable for the patient [9]. These lists are generated by specialty societies. Choosing Wisely ${ }^{\circledR}$ recommendations, if applied, should promote a change in the paradigm: teaching us, through shared decision making, how to engage with patients informed about low-value testing. This insight should be integrated into the current medical education and the practice of emergency physicians. In 2016, the Society of Academic Emergency Medicine consensus conference proceedings on shared decision making stated that the patient should be put back to the centre of the diagnostic strategy [10]. Shared decision making should be an essential part of a multipronged approach to reduce over-testing. The practice of shared decision making should follow a specific framework such as SHARE (Supplementary Material Appendix 1) [11]. Shared decision making is not a way for the clinician to abdicate responsibility for the medical decision or an abandonment of the patient, but implies that the final decision is made by the clinician and the patient together. As emergency physicians adapt to the increasing complexities of emergency care, time remains the most difficult resource to manage. In addition, time is needed for this strategy. Shared decision making is unlikely to be the only solution to improve quality of care in $\mathrm{ED}$, but it could be an additional tool, provided that the clinical situations for which such an approach would be necessary are clearly identified. This strategy should be taught to students, encouraged, and scientifically evaluated to assess its benefit both on patients and on the organization of ED (i.e., use of resources and congestion). It is essential to remember that the evidencebased medical paradigm includes patient values as one of its three fundamental principles. The patient is not an object of care but an actor of care.

Supplementary Information The online version contains supplementary material available at https://doi.org/10.1007/s43678-021-00231-7.

\section{Declarations}

Conflict of interest The author declares that they have no competing interest.

\section{References}

1. Carpenter CR, Raja AS, Brown MD. Overtesting and the downstream consequences of overtreatment: implications of "preventing overtreatment" for emergency Medicine. Acad Emerg Med. 2015;22(12):1484-92. https://doi.org/10.1111/acem.12820.

2. Kanzaria HK, Hoffman JR, Probst MA, et al. Emergency physician perceptions of medically unnecessary advanced diagnostic imaging. Acad Emerg Med. 2015;22(4):390-8. https://doi.org/10. 1111/acem. 12625.

3. Hussey PS, Wertheimer S, Mehrotra A. The association between health care quality and cost: a systematic review. Ann Intern Med. 2013;158(1):27-34. https://doi.org/10.7326/0003-4819-158-1201301010-00006.

4. Wiener RS, Schwartz LM, Woloshin S. Time trends in pulmonary embolism in the United States: evidence of overdiagnosis. Arch Intern Med. 2011;171(9):831-7. https://doi.org/10.1001/archi nternmed.2011.178.

5. Singer AJ Jr, Thode HC, Viccellio P, et al. The association between length of emergency department boarding and mortality. Acad Emerg Med. 2011;18(12):1324-9. https://doi.org/10.1111/j. 1553-2712.2011.01236.x.

6. Ugglas BJ, Djari T, Ljungman PLS, et al. Emergency department crowding associated with increased 30-day mortality: a cohort study in Stockholm Region, Sweden, 2012 to 2016. J Am Coll Emerg Physicians Open. 2020;1(6):1312-9. https://doi.org/10. 1002/emp2.12243.

7. Kohn MA, Carpenter CR, Newman TB. Understanding the direction of bias in studies of diagnostic test accuracy. Acad Emerg Med. 2013;20(11):1194-206. https://doi.org/10.1111/acem. 12255 .

8. Lord SJ, Irwig L, Simes RJ. When is measuring sensitivity and specificity sufficient to evaluate a diagnostic test, and when do we need randomized trials? Ann Intern Med. 2006;144(11):850-5. https://doi.org/10.7326/0003-4819-144-11-200606060-00011.

9. Levinson W, Kallewaard M, Bhatia RS, et al. 'Choosing Wisely': a growing international campaign. BMJ Qual Saf. 2015;24(2):16774. https://doi.org/10.1136/bmjqs-2014-003821.

10. Barrett TW, Rising KL, Bellolio MF, et al. The 2016 academic emergency medicine consensus conference, "shared decision making in the emergency department: development of a policy-relevant patient-centered research agenda" diagnostic testing breakout session report. Acad Emerg Med. 2016;23(12):1354-61. https:// doi.org/10.1111/acem.13050.

11. Agency for Healthcare Research and Quality. The SHARE approach. https://www.ahrq.gov/health-literacy/professional-train ing/shared-decision/index.html. Accessed 13 Sep 2021. 